\title{
Morphology and hydrolytic activity of A7, a typing phage of Pseudomonas syringae pv. morsprunorum
}

\author{
A. R. W. Smith, ${ }^{1}$ S. E. Zamze' + and R. C. Hignett ${ }^{2}$ \\ Author for correspondence: A. R. W. Smith. Tel: +4481316 8221. Fax: +44813168305.
}

1 School of Biological and Chemical Sciences, University of Greenwich Wellington St, London SE18 6PF, UK

2 Department of Science, Mid-Kent College of Higher and Further Education, Horstead, Maidstone Road, Chatham ME5 9UQ, UK

\begin{abstract}
Bacteriophage A7 has been employed as an indicator for strains of Pseudomonas syringae pv. morsprunorum race 1. Electron microscopy showed that this phage had a hexagonal head, $59 \mathrm{~nm}$ in diameter, and a long, flexible, non-contractile tail, $164 \mathrm{~nm}$ long and $8 \mathrm{~nm}$ wide, containing approximately 15 evenly spaced transverse striations and terminating in a base-plate equipped with six spikes arranged in a radially symmetrical pattern around a central core. Two short fibres projecting at an angle from the base-plate were also visible on some phage particles. Phage A7 can therefore be placed in group B of the classification system of Bradley. Phage particles bound at apparently random sites over the surface of host cells by their base-plates, and after a short time released DNA from their heads. Phage A7 uses lipopolysaccharide (LPS) as its binding site on the bacterial cell surface, removing the D-rhamnan side-chains by the action of a rhamnan hydrolase. The appearance of purified LPS by electron microscopy was either strand-like or vesicular, according to whether it had been stained with phosphotungstate or uranyl acetate respectively. Strands were of approximately uniform width (approx. $9 \mathrm{~nm}$ ). Vesicular forms included both circles, 25-45 $\mathrm{nm}$ in diameter, and larger oval structures of greater electron transparency. The appearance of the LPS did not alter on addition of the phage. Phage particles were observed attached via their base-plates to LPS vesicles, in particular the larger oval vesicles, but were never seen attached to strands. The heads of phage particles attached to LPS were frequently empty. The rhamnanase of phage A7 released the side-chain residues from the LPS as an equimolar mixture of tri- and hexasaccharide. By using ' $\mathrm{H}-\mathrm{NMR}$ spectroscopy and methylation analysis, the site of cleavage has been identified as the 2$)-\alpha-D-R h a p(1 \rightarrow 3)$ residue.
\end{abstract}

Keywords: Pseudomonas syringae pv. morsprunorum, bacteriophage, lipopolysaccharide

\section{INTRODUCTION}

Cherry and plum strains of the phytopathogen Pseudomonas syringae pv. morsprunorum are the main cause of bacterial canker on their respective host plants in England (Garrett et al., 1966). Although cherry and plum isolates are indistinguishable using routine biochemical and physiological tests, they can be differentiated by bacteriophage typing (Crosse \& Garrett, 1963, 1970). This method has revealed two distinct pathological groups with a high

Abbreviation: PMAA, partially-methylated alditol acetate.

†Present address: Glycobiology Unit, Department of Biochemistry, University of Oxford, South Parks Road, Oxford OX1 3QU, UK. degree of specificity for their homologous hosts in the field. Crosse \& Garrett $(1963,1970)$ found that all cherry isolates were sensitive to A7, the main typing phage, and to several related phages, but almost all plum isolates tested were resistant.

Later work by Freigoun \& Crosse (1975) led to the isolation of variant (race 2) cherry strains that showed altered physiological, pathological and phage typing characteristics compared with those of the original (race 1 ) isolates. Approximately one-third of the race 2 strains tested were insensitive to phage A7, and showed a closer resemblance in their pathology to $P$. syringae pv. syringae than to pv. morsprunorum (Garrett \& Martins, 1976; Garrett et al., 1977). 
The receptor for phage A7 on the bacterial cell surface is the lipopolysaccharide (LPS) (Quirk et al., 1976). Despite differences in phage susceptibility, both plum and cherry isolates adsorb A7 with equal efficiency (Garrett $e t$ al., 1974), indicating that all these strains contain the LPS receptor site for the phage. The reason for resistance of the plum and race 2 cherry isolates to phage A7 is not known.

The chemical composition of the LPS from several cherry and plum isolates is now known (Smith et al., 1984, 1985a, b; Zamze et al., 1985, 1986). The side-chain polysaccharide of the LPS from strain C28, a virulent race 1 cherry isolate, is a polymer of D-rhamnose with the following repeat unit structure, which has also been found in the side-chain of LPS from a strain described as Pseudomonas cerasi 467 by Knirel et al. (1988), and interestingly is also identical with the structure of Pseudomonas common antigen (Yokota et al., 1990):

3)- $\alpha$-D-Rhap $p(1 \rightarrow 3)-\alpha$-D-Rhap-(1 $\rightarrow 2)-\alpha-$ D-Rha $p-(1 \rightarrow$

During infection, the phage hydrolyses the side-chains of this LPS, liberating them as oligosaccharide (Smith et al., 1985a, b). Mutation of sensitive organisms to phage resistance is coupled with production of rough LPS and loss of the ability to adsorb the phage, together with loss of virulence (Garrett et al., 1974; Zamze et al., 1985).

In this paper, we report an electron-microscopic study of phage A7 and its interaction with LPS, and describe the characterization of the cleavage site for phage A7 rhamnanase within the side-chain polysaccharide of LPS from strain C28. Preliminary reports on this work were given earlier by Smith et al. $(1984,1992)$.

\section{METHODS}

Organisms. Pseudomonas syringae pv. morsprunorum isolates C28 (from cherry) and D10 (from plum), and phage A7 were originally provided by Dr C. M. E. Garrett, Horticulture Research International (HRI), East Malling, Maidstone, Kent, UK, and were maintained as described by Smith et al. (1985a).

Bulk culture of bacteria and extraction of LPS. Bulk culture of strains C28 and D10, and extraction of and purification of LPSs therefrom, were all carried out as previously described (Smith et al., 1985a, b).

Electron microscopy. Prior to examination, phage suspensions containing $10^{11}$ p.f.u. $\mathrm{ml}^{-1}$ were passed through $0.22 \mu \mathrm{m}$ porosity Millipore filters. Cells of strain C28 were taken from 18-h-old nutrient-glycerol agar slopes, washed twice in filtered distilled water and finally resuspended to a concentration of $10^{8}$ c.f.u. $\mathrm{ml}^{-1}$.

Phage particles were allowed to adsorb to bacteria by mixing $0.1 \mathrm{ml}$ phage suspension with $0.1 \mathrm{ml}$ bacterial suspension. Mixtures were incubated at $20^{\circ} \mathrm{C}$, and samples were withdrawn for examination at various times between $30 \mathrm{~s}$ and $1 \mathrm{~h}$.

To examine the interaction between phage A7 and LPS in vitro, $0 \cdot 1 \mathrm{ml}$ LPS solution $\left(100 \mu \mathrm{g}\right.$ dry weight $\mathrm{ml}^{-1}$ ) was mixed with an equal volume of phage suspension and incubated for $30 \mathrm{~min}$ at $20^{\circ} \mathrm{C}$.
Samples for staining were spotted onto Formvar/carbon-coated electron micrograph grids and allowed to stand at room temperature for $30-60 \mathrm{~s}$. Most of the droplet was removed by touching the edge of the grid with filter paper. The stain, $10 \mu \mathrm{l}$ of either $2 \%(\mathrm{w} / \mathrm{v})$ sodium phosphotungstate, $\mathrm{pH} 6.7$, or uranyl acetate, $(1-2 \%, \mathrm{w} / \mathrm{v})$, was applied immediately, and the grids were allowed to stand for a further $15 \mathrm{~s}$ before removing the excess with filter paper. For the examination of aqueous solutions of LPS, grids were pretreated for $1 \mathrm{~min}$ with a solution of $0.01 \%(\mathrm{w} / \mathrm{v})$ bovine serum albumin as a wetting agent. Grids were examined in an AEI model EM6B electron microscope at the magnifications specified in Results.

Carbohydrate analysis. Carbohydrate was detected using phenol/sulphuric acid (Dubois et al., 1956). Oligosaccharides were hydrolysed with $0.5 \mathrm{M} \mathrm{HCl}$ for $3.5 \mathrm{~h}$ at $100{ }^{\circ} \mathrm{C}$ to liberate the monosaccharides, which were converted to their alditol acetates for analysis by GC (Zamze et al., 1986).

Oxidation of side-chains. Intact side-chains were isolated from LPS by hydrolysis with $1 \%(\mathrm{v} / \mathrm{v})$ acetic acid or $0.01 \mathrm{M} \mathrm{HCl}$ and gel filtration as previously described (Smith et al., 1985a, b). Side-chain material $(2 \mu \mathrm{mol}$ rhamnose) was oxidized with sodium periodate, reduced with sodium borohydride and freed of salts by chromatography on Sephadex G-25, using previously-described procedures (Smith et al., 1985b).

Side-chain hydrolysis by phage A7 rhamnanase and purification of products. Phage A7 particles were pelleted from stock suspensions (10-50 ml, containing $10^{12}$ p.f.u. $\mathrm{ml}^{-1}$ ) by centrifugation at $40000 \mathrm{~g}$ for $1 \mathrm{~h}$, washed once and resuspended in distilled water $(1-5 \mathrm{ml})$. Particles $\left(10^{12}\right.$ p.f.u. per $\mathrm{mg}$ LPS added) were then mixed with LPS $(90 \mathrm{mg})$ in a total volume of $60 \mathrm{ml}$, and incubated at room temperature with occasional shaking for $2 \mathrm{~h}$. The mixture was then ultracentrifuged at $100000 \mathrm{~g}$ for $3 \mathrm{~h}$ to deposit high- $M_{\mathrm{r}}$ components. The supernatant was heated to $100^{\circ} \mathrm{C}$ for $5 \mathrm{~min}$ to inactivate rhamnanase, dried by rotary evaporation at $40^{\circ} \mathrm{C}$ in vacuo, and the residue was taken up in methanol and centrifuged at $5000 \mathrm{~g}$ for $10 \mathrm{~min}$. The supernatant was re-evaporated, taken up in $2 \mathrm{ml}$ pyridine/acetic acid buffer $(0.05 \mathrm{M}, \mathrm{pH} 5.4)$, and applied to a column $(41 \times 2 \mathrm{~cm})$ of Sephadex G-25 equilibrated with the same buffer, calibrated for $M_{\mathrm{r}}$ determinations with glucose, lactose, raffinose and stachyose (authentic mono-, di-, tri- and tetrasaccharides respectively; Smith et al., 1984). Elution was at $0.3 \mathrm{ml} \mathrm{min}^{-1}$ with collection of $3.9 \mathrm{ml}$ fractions, of which $0.05 \mathrm{ml}$ portions were assayed for carbohydrate with phenol/sulphuric acid reagent.

Samples of the oligosaccharides $(3-6 \mathrm{mg}$ ) pooled from gel filtration were reduced with sodium borohydride, acidified with acetic acid and freed of salts as described above.

Methylation analysis of oligosaccharides. Native or reduced oligosaccharides (3-6 mg) were methylated and analysed as described by Smith et al. (1985b). Methylation products were recovered by extraction with chloroform, evaporated to dryness, taken up in diethyl ether, centrifuged, re-evaporated, dissolved in methanol, and purified using a column $(17 \times 2.5 \mathrm{~cm})$ of Sephadex LH-20 eluted with methanol. The methylated oligosaccharides, which were recovered in about $60 \%$ yield, were hydrolysed, reduced and acetylated to form partiallymethylated alditol acetates (PMAAs), and analysed by GC-MS.

${ }^{1}$ H-NMR spectroscopy. Native or reduced oligosaccharide (3-6 mg) was lyophilized five times from solution in $99.8 \%$ $\mathrm{D}_{2} \mathrm{O}$, and finally dissolved in $100 \% \mathrm{D}_{2} \mathrm{O}$. Spectra from about 200 scans were recorded at $400 \cdot 13 \mathrm{MHz}$ using a Bruker WH-400 spectrometer at both $24^{\circ} \mathrm{C}$ and $60^{\circ} \mathrm{C}$, relative to internal acetone $(\delta=2.23$ p.p.m.), with a pulse width of $4.0 \mu$ s and an acquisition time of $3.01 \mathrm{~s}$. 

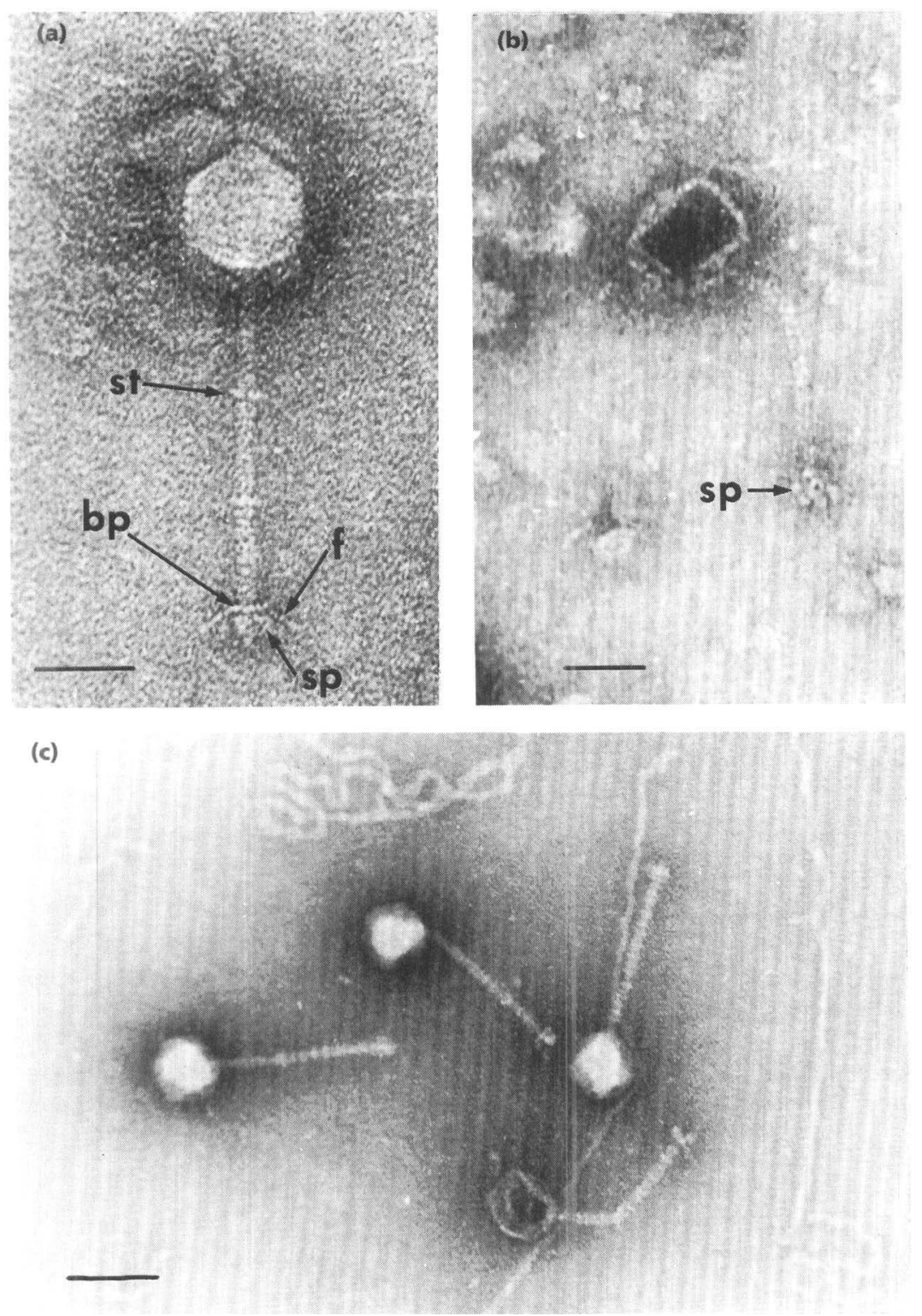

Fig. 1. Morphology of phage A7. (a) Phage particle stained with uranyl acetate. The tail displays transverse striations (st) and terminates in a base-plate (bp) equipped with spikes (sp). Two short fibres (f) are sometimes seen attached to the base-plate, projecting at an angle. Bar, $50 \mathrm{~nm}$. (b) Phage tail turned to reveal the base-plate end-on. Six tail spikes (sp) are present, arranged in a radially symmetrical pattern around a central core. Stained with uranyl acetate. Bar, $50 \mathrm{~nm}$. (c) Phage/LPS mixtures stained with phosphotungstate, showing approximately 15 evenly spaced striations on each tail. Note the lack of attachment of the phage to the LPS strands. Bar, $100 \mathrm{~nm}$.

\section{RESULTS}

\section{Electron microscopy of phage A7 and LPS}

Phage A7 had a hexagonal head, $59 \mathrm{~nm}$ in diameter and a long, flexible, non-contractile tail, $164 \mathrm{~nm}$ long and $8 \mathrm{~nm}$ wide (Fig. 1a). The tail terminated in a base-plate equipped with six tail spikes arranged in a radially symmetrical pattern around a central core (Fig. 1b). Two short fibres attached to and projecting at an angle from the base-plate were also visible on some phage particles (Fig. 1a). Although fine details of phage structure were generally better observed on electron micrographs of material stained with uranyl acetate, the use of phosphotungstate more clearly revealed the presence of approximately 15 evenly spaced striations on each tail (Fig. 1c). Phage tails and heads were often seen in isolation, possibly as a result of shearing during Millipore filtration.

The phage attached to the bacterial cell surface by its base- plate (Fig. 2a). Bound particles were observed within 1 min of incubation (Fig. 2b) in apparently random distribution over the surface of the bacterium. There was a discernible latent period between the initial binding and the eclipse of the phage; the proportion of adsorbed phages that had ejected their DNA (those phages whose emptied heads had filled with the electron-dense stain) increased up to $1 \mathrm{~h}$ incubation, by which time infected bacterial cells had begun to round off in preparation for lysis.

Samples of LPS from strain C28 appeared either as strands or vesicular structures according to whether they had been stained with phosphotungstate or uranyl acetate respectively (Figs $3 a, b$ and 4 ). LPSs from various strains of $P$. syringae pvs. morsprunorum and syringae all gave the same appearance. The morphology of the aggregates showed this same disparity whether or not the grids were pre-treated with bovine serum albumin, and regardless of 

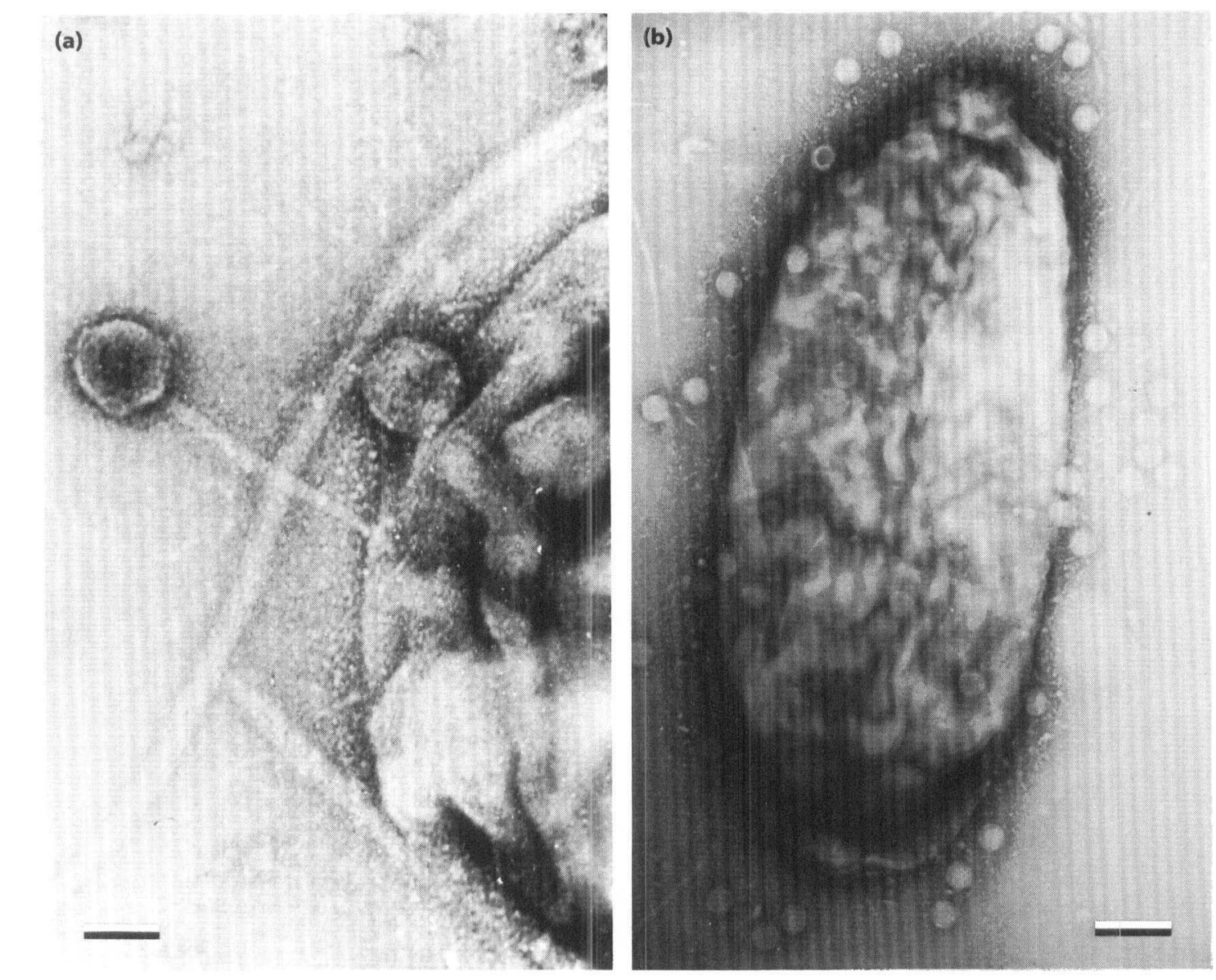

Fig. 2. Attachment of phage $A 7$ to cells of $P$. syringae pv. morsprunorum strain C28. (a) Phage particles attached to a cell by their base-plates. Sample stained with uranyl acetate. Bar, $50 \mathrm{~nm}$. (b) Bacterial cells sampled within 1 min of infection with phage. The phage binds to the surface of the bacterium. Bar, $200 \mathrm{~nm}$.

the $\mathrm{pH}$ value $(3-10)$ of the phosphotungstate solution. The addition of phage particles to LPS did not affect its appearance (Figs $1 \mathrm{~b}$ and 4 ).

The strands or filaments revealed with phosphotungstate were of constant width (approx. $9 \mathrm{~nm}$ ) but of indeterminate length, and were variously branched, unbranched, open-ended or in the form of closed circles. Within the strands, small regions of greater electron transparency were observed.

The vesicles revealed with uranyl acetate included both circular and oval forms; the latter were more electrontransparent. The diameter of most circular bodies fell within the range $25-45 \mathrm{~nm}$; the width of oval bodies varied between 34 and $63 \mathrm{~nm}$ along the long axis and between 13 and $21 \mathrm{~nm}$ along the short. In some instances circular bodies appeared to have merged to form laiger aggregates, and some aggregates were extended to give the appearance of strands. The apparently circular and oval forms may have been generated by identical vesicular structures differing only in their orientation on the grid (compare the observations of Shands et al., 1967), the circles representing bodies lying flat, and the oval electron-transparent forms being oriented with their long axes aligned vertically, which would imply ellipsoidal structures.

When incubated with LPS and stained with uranyl acetate, phage particles were subsequently seen attached to the vesicles via their base-plates (Fig. 4). In contrast, staining with phosphotungstate did not reveal phage attachment to the stranded form of LPS (Fig. 1c). Examination of a number of grids suggested that the phage attached preferentially to the larger oval forms, which were also more electron-transparent, than to other oval or circular forms. The heads of attached phages were frequently empty (Fig. 4). Identical observations were made when purified LPS from the plum isolate D10 was mixed with phage A7. Strain D10 is insensitive to lysis by this phage, but adsorbs A7 to its surface, and incubation of the purified LPS from this strain with phage A7 also leads to phage inactivation.

\section{Hydrolytic activity of phage A7 towards LPS}

A mixture of phage $\left(9 \times 10^{13}\right.$ p.f.u. $)$ and LPS of strain C28 $(90 \mathrm{mg})$ was incubated at room temperature for $2 \mathrm{~h}$, and ultracentrifuged as described in Methods to pellet the 

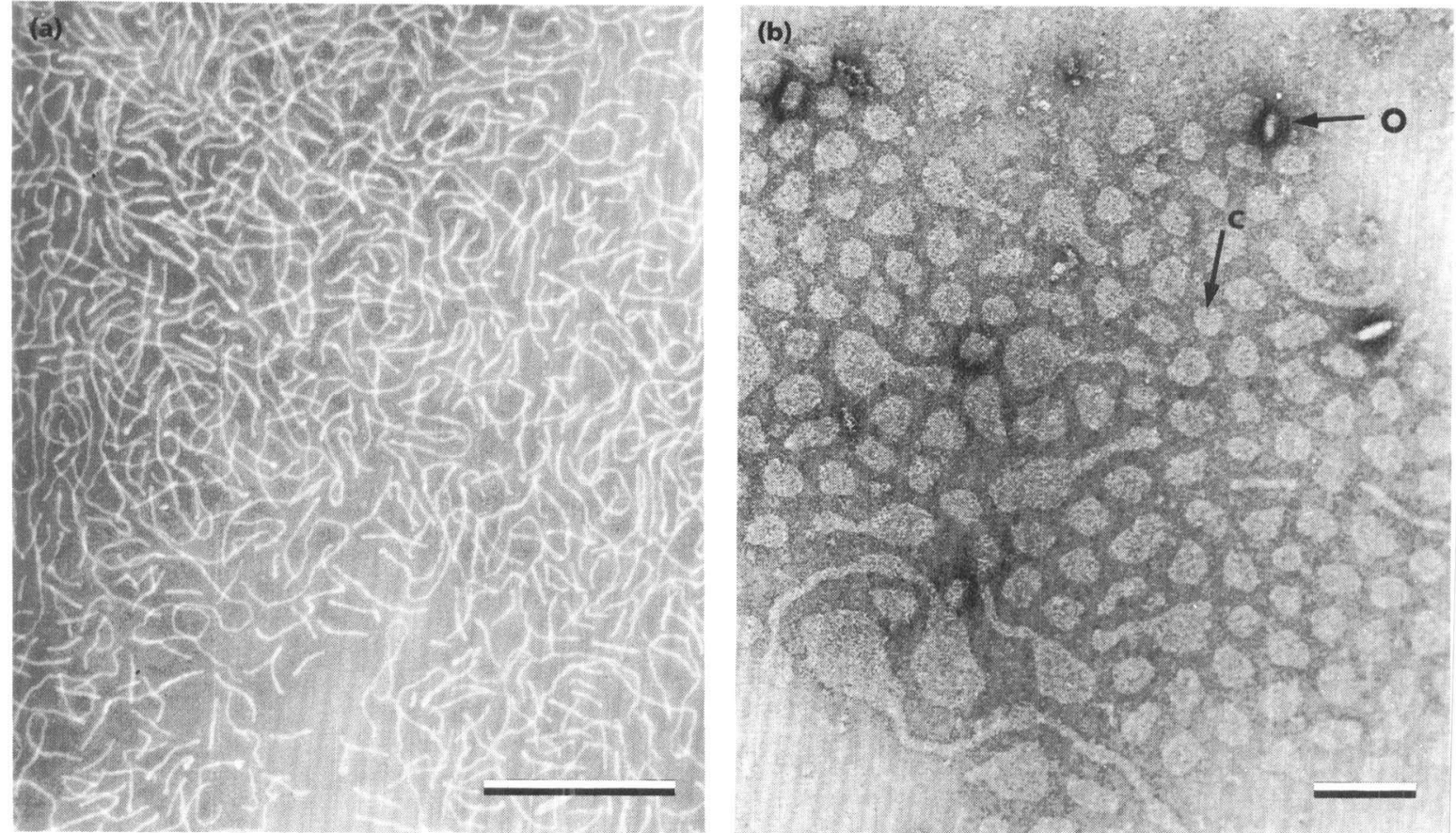

Fig. 3. LPS from $P$. syringae pv. morsprunorum strain C28 stained with phosphotungstate and uranyl acetate. (a) LPS stained with phosphotungstate, appearing as strands or filaments. Bar, $500 \mathrm{~nm}$. (b) LPS stained with uranyl acetate, appearing as vesicular bodies including both circular structures (c), and oval structures $(O)$ of greater electron transparency. Bar, $100 \mathrm{~nm}$.

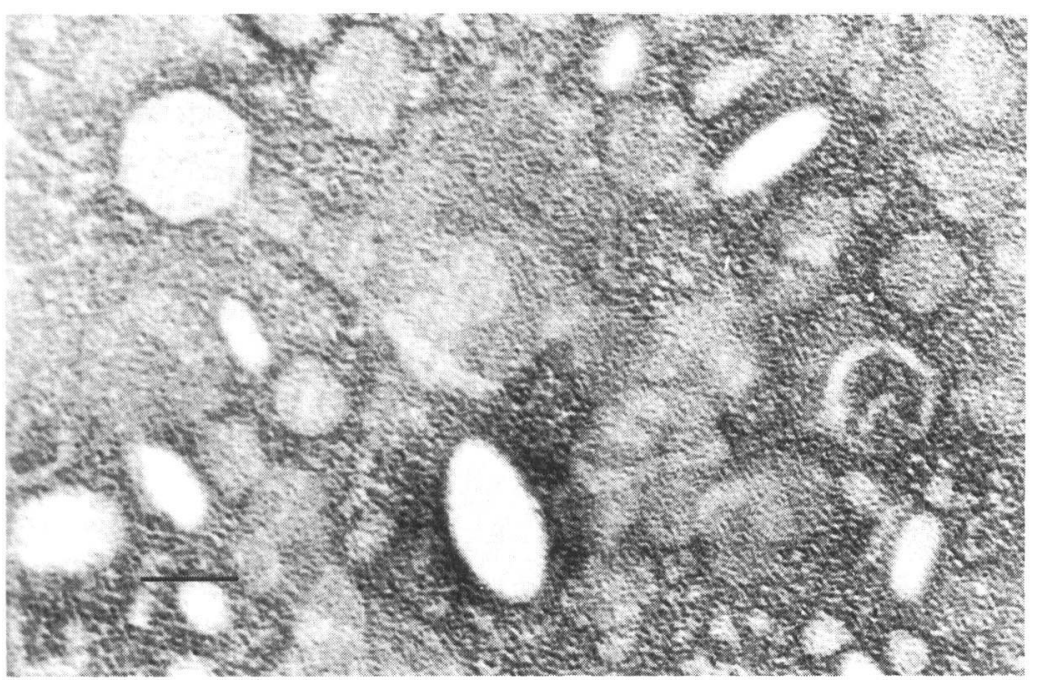

Fig. 4. LPS from $P$. syringae pv. morsprunorum strain C28 incubated with phage A7 and stained with uranyl acetate. Note the attachment of the phage to the LPS vesicle via its base-plate. Bar, $50 \mathrm{~nm}$. core-lipid A component and any residual intact LPS. The supernatant, containing the depolymerized side-chain polysaccharide, was evaporated to dryness, and further purified by dissolution in methanol followed by centrifugation at low speed, which produced a water-soluble pellet containing no carbohydrate. Chromatography of the carbohydrate fraction on a column of Sephadex G-25 previously calibrated for $M_{\mathrm{r}}$ determinations yielded two closely-eluting peaks, A and B (Fig. 5), which were separated by repeated chromatographic fractionation. The $M_{\mathrm{r}}$ of the material in peak A (oligosaccharide I) was estimated to be about 880 ; the $M_{\mathrm{r}}$ for peak B material (oligosaccharide II) was about 440: these values are consistent with hexasaccharide and trisaccharide respectively. The molar ratio of the two oligosaccharides was approximately unity.

If dissolution in methanol was omitted from the purification procedure, the oligosaccharides did not separate when chromatographed on Sephadex G-25, yielding instead an indeterminate peak of apparent $M_{\mathrm{r}}$ approximately 900 . The reason for this has not been investigated. 


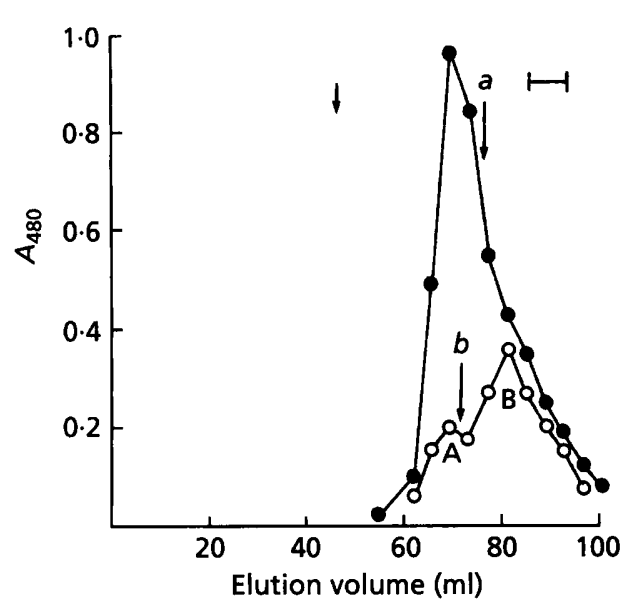

Fig. 5. Fractionation on Sephadex G-25 of oligosaccharides produced by incubation of LPS from strain C28 with phage A7. The low- $M_{\mathrm{r}}$ products resulting from incubating LPS $(90 \mathrm{mg})$ of strain C28 with phage A7 $\left(9 \times 10^{13}\right.$ p.f.u.) were fractionated on a column $(41 \times 2 \mathrm{~cm})$ of Sephadex G-25. Elution was performed with $0.05 \mathrm{M}$ pyridine/acetic acid, $\mathrm{pH} 5.4$, at a flow rate of $0.3 \mathrm{ml} \mathrm{min}^{-1}$. In the first run, $3.9 \mathrm{ml}$ fractions were collected and $0.05 \mathrm{ml}$ portions were assayed for total carbohydrate (O, measured at $480 \mathrm{~nm}$ ). Fractions eluting before a were pooled and were found to contain oligosaccharide I alone. To obtain oligosaccharide II, the fractions emerging after a were pooled, evaporated and re-applied to the column, which was run under the same conditions as above, and assayed as above for total carbohydrate $(O)$. Fractions eluting before $b$ contained more oligosaccharide I, and were accordingly re-combined with the bulk of oligosaccharide I. The fractions emerging after $b$ were pooled separately to obtain the oligosaccharide II. The vertical arrow indicates $V_{0}$; the horizontal bar, $V_{i}$.

Although the phage could also hydrolyse isolated sidechains, modification of the isolated side-chains by periodate oxidation, followed by reduction with sodium borohydride, completely prevented phage-mediated hydrolysis. The same treatment of whole LPS prevented both hydrolysis of side-chains and inactivation of the phage.

\section{Characterization of oligosaccharides}

Analysis by GC of the alditol acetates derived from oligosaccharides I and II revealed the presence of only rhamnitol penta-acetate.

The two oligosaccharides and their reduced derivatives were examined by ${ }^{1} \mathrm{H}-\mathrm{NMR}$ spectroscopy (Table 1). The signals in the anomeric region of the spectrum for oligosaccharide II, taken at $24{ }^{\circ} \mathrm{C}$, revealed three singlet signals of approximately equal intensity at $4.96,5.05$ and $5 \cdot 24$ p.p.m., which were attributed to anomeric protons of $\alpha$-rhamnopyranose residues, in a pattern closely similar to that obtained for the intact side-chain of strain C28 (Smith et al., 1985b). The anomeric signals in the spectrum for oligosaccharide I at $24^{\circ} \mathrm{C}$ consisted of five singlet signals of approximately equal intensity: one at 4.95-4.97 (two protons), and the remainder at 5.03, 5.05, 5.23 and
Table 1. 'H-NMR signals in the anomeric regions of the spectra for the native and reduced oligosaccharides $I$ and II

Native and reduced oligosaccharides I (3 mg each) and II (6 mg each) were prepared for ${ }^{1} \mathrm{H}-\mathrm{NMR}$ spectroscopy as described in Methods. Spectra were recorded at $24^{\circ} \mathrm{C}$ from 220 scans in $100 \% \mathrm{D}_{2} \mathrm{O}$ at $400 \cdot 13 \mathrm{MHz}$ relative to acetone as the internal standard ( $\delta=2.23$ p.p.m.). Braces indicate signals that may be assigned in reverse order.

\begin{tabular}{|c|c|c|c|}
\hline \multirow[t]{2}{*}{ Residue } & \multirow{2}{*}{$\begin{array}{l}\text { Signal } \\
\text { (p.p.m.) }\end{array}$} & \multicolumn{2}{|c|}{ Numbers of: } \\
\hline & & $\begin{array}{c}\text { Anomeric } \\
\text { protons }\end{array}$ & $\begin{array}{l}\text { Methyl } \\
\text { protons }\end{array}$ \\
\hline \multicolumn{4}{|l|}{ Oligosaccharide II } \\
\hline$\rightarrow 2)-\beta-\mathrm{Rha} p-\mathrm{OH}^{*}$ & $4 \cdot 89$ & $0 \cdot 1$ & \multirow{4}{*}{9} \\
\hline$\alpha-\operatorname{Rhap}(1 \rightarrow$ & 4.96 & 1 & \\
\hline$\rightarrow 3)-\alpha-\operatorname{Rha} p(1 \rightarrow$ & $5 \cdot 05$ & 1 & \\
\hline$\rightarrow 2)-\alpha-\mathrm{Rhap}-\mathrm{OH}$ & $5 \cdot 24$ & $0 \cdot 9$ & \\
\hline \multicolumn{4}{|c|}{ Reduced oligosaccharide II } \\
\hline$\alpha-\operatorname{Rha} p(1 \rightarrow$ & $4 \cdot 94$ & 1 & \multirow{3}{*}{9} \\
\hline$\rightarrow 3)-\alpha-\operatorname{Rha} p(1 \rightarrow$ & 5.07 & 1 & \\
\hline$\rightarrow 2$ )-Rha-ol & - & & \\
\hline \multicolumn{4}{|l|}{ Oligosaccharide I } \\
\hline$\rightarrow 2)-\beta$ - Rhap $-\mathrm{OH}^{*}$ & $4 \cdot 89$ & $0 \cdot 1$ & \multirow{6}{*}{18} \\
\hline $\left.\begin{array}{rl}\alpha-\operatorname{Rha} p(1 & \rightarrow \\
\rightarrow 3)-\alpha-\operatorname{Rha} p(1 & \rightarrow\end{array}\right\}$ & $4.95-4.97$ & 2 & \\
\hline$\rightarrow 3)-\alpha-$ Rhap $(1 \rightarrow$ & $5 \cdot 03$ & 1 & \\
\hline$\rightarrow 3)-\alpha-\operatorname{Rha} p(1 \rightarrow$ & $5 \cdot 05$ & 1 & \\
\hline$\rightarrow 2)-\alpha-\operatorname{Rhap}(1 \rightarrow\{$ & $5 \cdot 23$ & 1 & \\
\hline$\rightarrow 2)-\alpha-\mathrm{Rha} p-\mathrm{OH}$ & $5 \cdot 24$ & $0 \cdot 9$ & \\
\hline \multicolumn{4}{|c|}{ Reduced oligosaccharide I } \\
\hline$\alpha-\operatorname{Rhap}(1 \rightarrow\{$ & 4.92 & 1 & \multirow{5}{*}{18} \\
\hline$\rightarrow 3)-\alpha-\operatorname{Rhap}(1 \rightarrow$ L & 4.97 & 1 & \\
\hline$\rightarrow 3)-\alpha-\mathrm{Rha} p(1 \rightarrow$ & $5 \cdot 03-5 \cdot 06$ & 2 & \\
\hline$\rightarrow 2)-\alpha-\operatorname{Rha} p(1 \rightarrow$ & $5 \cdot 21$ & 1 & \\
\hline$\rightarrow 2$ )-Rha-ol & - & & \\
\hline
\end{tabular}

* From spectra taken at $60^{\circ} \mathrm{C}$.

5.24 p.p.m. (one proton each), which were likewise attributed to $\alpha$-rhamnopyranose residues. At $60^{\circ} \mathrm{C}$, the $\mathrm{DOH}$ peak was moved to higher field to reveal small peaks in the spectra of both oligosaccharides at 4.89 p.p.m., probably attributable to $\mathrm{H}-1$ of $\beta$ rhamnopyranose at the reducing termini.

The spectrum of the reduced form of oligosaccharide II at $24{ }^{\circ} \mathrm{C}$ revealed only two singlet anomeric signals at 4.94 and 5.07 p.p.m. of approximately equal intensity; the signal at 5.24 p.p.m. had been abolished. In the spectrum of reduced oligosaccharide I at $24{ }^{\circ} \mathrm{C}$, there were five singlet signals of approximately equal intensity at 4.92 , 4.97 and 5.21 p.p.m. (one proton each) and 5.03-5.06 (two protons). As with oligosaccharide II, the signal at 5.24 p.p.m. had disappeared, which was consistent in both cases with the reduction of a reducing terminal 2- 
Table 2. Identities and molar ratios of PMAAs derived from oligosaccharides I and II and their reduction products

Components were identified by GC of partially methylated alditol acetates on 3\% ECNSS-M. Peak areas were adjusted using correction factors based on the effective carbon response (Sweet $e t$ al., 1975), and ratios are expressed after setting the quantity of $3,4-\mathrm{Me}_{2} \mathrm{Rha}=1.00$ for an internal residue, or 0.64 for a reducing terminal residue, where the corresponding quantity of $3,5-\mathrm{Me}_{2} \mathrm{R}$ ha would be $0 \cdot 36$. Triand hexasaccharides were reduced at their reducing termini with $\mathrm{NaBH}_{4}$. For further details, see Methods.

\begin{tabular}{|c|c|c|c|c|c|}
\hline \multirow[t]{2}{*}{ Peak } & \multirow[t]{2}{*}{ Identity* } & \multirow[t]{2}{*}{$\boldsymbol{R}_{\mathrm{t}} \dagger$} & \multirow{2}{*}{$\begin{array}{l}\text { Mass spectrometry: } \\
\text { primary ions }(m / z)\end{array}$} & \multicolumn{2}{|c|}{ Molar ratios } \\
\hline & & & & Native & Reduced \\
\hline \multicolumn{6}{|c|}{ Oligosaccharide II } \\
\hline 1 & $2,3,4-\mathrm{Me}_{3} \mathrm{Rha}$ & $0 \cdot 42$ & $117,131,161$ & $0 \cdot 70$ & $1 \cdot 0$ \\
\hline 2 & $3,5-\mathrm{Me}_{2} \mathrm{Rha}$ & $0 \cdot 83$ & $59,175,189$ & $0 \cdot 0$ & $0 \cdot 0$ \\
\hline 3 & $3,4-\mathrm{Me}_{2} \mathrm{Rha}$ & 0.91 & 131,189 & 0.64 & $0 \cdot 0$ \\
\hline 4 & $2,4-\mathrm{Me}_{2} \mathrm{Rha}$ & $1 \cdot 01$ & 117,131 & $1 \cdot 40$ & $1 \cdot 15$ \\
\hline \multicolumn{6}{|c|}{ Oligosaccharide I } \\
\hline 1 & $2,3,4-\mathrm{Me}_{3} \mathrm{Rha}$ & $0 \cdot 42$ & $117,131,161$ & $0 \cdot 88$ & $0 \cdot 79$ \\
\hline 2 & $3,5-\mathrm{Me}_{2} \mathrm{Rha}$ & $0 \cdot 83$ & $59,175,189$ & $0 \cdot 36$ & $0 \cdot 0$ \\
\hline 3 & $3,4-\mathrm{Me}_{2} \mathrm{Rha}$ & $0 \cdot 91$ & 131,189 & $1 \cdot 64$ & $1 \cdot 00$ \\
\hline 4 & $2,4-\mathrm{Me}_{2} \mathrm{Rha}$ & $1 \cdot 01$ & 117,131 & $4 \cdot 01$ & $3 \cdot 39$ \\
\hline
\end{tabular}

$* 2,3,4-\mathrm{Me}_{3} \mathrm{Rha}=2,3,4$-tri-O-methylrhamnitol 1,5-diacetate, etc.

$\dagger R_{t}$, retention time relative to that of $2,3,4,6-\mathrm{Me}_{4} \mathrm{Glc}$.

substituted rhamnose residue. Taking into account the structure of the intact side-chain polysaccharide (Smith $e t$ al., 1985b), the data from the ${ }^{1} \mathrm{H}-\mathrm{NMR}$ spectra indicated the following structures.

Oligosaccharide I:

$\alpha$-D-Rhap- $(1 \rightarrow 3)-\alpha-$ D-Rhap- $(1 \rightarrow 2)-\alpha-$ D-Rha $p-(1 \rightarrow 3)-$ $\alpha$-D-Rha $p$ - $(1 \rightarrow 3)-\alpha$-D-Rha $p$ - $(1 \rightarrow 2)-$ D-Rha

Oligosaccharide II :

$\alpha$-D-Rhap-(1 $\rightarrow 3)-\alpha$-D-Rhap-(1 $\rightarrow 2)$-D-Rha

The corresponding reduction products bore D-rhamnitol at the reducing termini.

Results of methylation analysis of the native and reduced forms of oligosaccharides I and II are given in Table 2, which shows the identity and approximate molar ratio of each component, and significant mass spectral data for the constituent components.

All samples tended to give low yields of 2,3,4-tri-Omethylrhamnitol 1,5-diacetate, probably either because of its relative volatility, or because of under-methylation of, or selective demethylation at the 3-position on the non-reducing terminus, since the yields of 2,4-di-Omethylrhamnitol 1,3,5-triacetate tended to be higher than expected. With allowances for this observation, the results of methylation analysis were broadly consistent with identification of oligosaccharide I as the hexasaccharide shown above, in which the reducing terminal was 2substituted, and was methylated in both the pyranosidic $(64 \%)$ configuration to give 3,4-di-O-methylrhamnitol 1,2,5-triacetate, and the furanosidic (36\%) form to give 3,5-di-O-methylrhamnitol 1,2,4-triacetate (Björndal et al., 1970). Berry \& Dutton (1972) also observed that the use of the Hakomori procedure led to the formation of a high proportion of the furanosidic isomer (approx. $40 \%$ ) from the reducing terminus of permethylated 6-O-(4-O-methyl$\beta$-D-glucopy ranosyl)-D-galactose.

The reduced hexasaccharide yielded $1 \mathrm{~mol}$ 2,3,4-tri-Omethylrhamnitol diacetate, $3 \mathrm{~mol}$ 2,4-di-O-methylrhamnitol triacetate, and only $1 \mathrm{~mol} 3,4-\mathrm{di}-\mathrm{O}$-methylrhamnitol triacetate, with none of the 3,5-di-O-methylrhamnitol derivative.

Methylation analysis of oligosaccharide II yielded 2,3,4tri-O-methylrhamnitol diacetate, and 2,4- and 3,4-di-Omethylrhamnitol triacetate, consistent with the structure shown above, though the expected 3,5-di-O-methylrhamnitol triacetate was unaccountably missing. Reduced oligosaccharide II yielded only 2,3,4-tri-O-methylrhamnitol diacetate and 2,4-di-O-methylrhamnitol triacetate in equimolar proportion. Derivatives from the terminal rhamnitol of the reduced oligosaccharides (e.g. 1,3,4,5tetra-O-methylrhamnitol monoacetate from a 2 -O-substituted residue) were not detected, probably because of their volatility.

The results of methylation analysis and ${ }^{1} \mathrm{H}-\mathrm{NMR}$ spectroscopy were therefore consistent with hydrolysis of the intact thamnan side-chain at 2$)-\alpha$-D-Rha $p(1 \rightarrow 3$ linkages to yield equal molar quantities of tri- and hexasaccharide products. 


\section{DISCUSSION}

Enterobacterial phages that use the side-chains of LPS as their recognition sites (O-antigen specific phages) have been well characterized, and have been reviewed by Lindberg (1977) and Wright et al. (1980). Binding of all these phages is accompanied by enzyme-catalysed hydrolysis of the receptor polysaccharide. This property is also a characteristic of phage $A 7$, which has been shown to degrade the side-chains of the LPS from $P$. syringae pv. morsprunorum strain C28 to tri- and hexasaccharide units. Characterization of these oligosaccharides revealed that A7 specifically cleaved the $\alpha(1 \rightarrow 3)$ glycosidic linkage of the residue substituted at $\mathrm{C} 2$, i.e. at 2$)-\alpha-\mathrm{D}-\mathrm{Rhap}(1 \rightarrow 3$. The trisaccharide was produced by cleavage at adjacent susceptible linkages: the hexasaccharide by cleavage at every second susceptible linkage. The products were obtained in approximately equal molar proportion. Oligosaccharides larger than the hexasaccharide were never detected, which indicates that A7 degrades the polysaccharide sequentially from the non-reducing terminus.

R-type LPS from rough mutants of strain C28 fails to inactivate A7 in vitro (Zamze et al., 1985), as do the isolated side-chains from the smooth LPS of C28 (Smith et al., 1985a), which suggests that intact smooth LPS is essential for phage inactivation and to trigger the release of phage DNA.

Phage A7 can hydrolyse isolated side-chains, though not after oxidation of the 2-substituted rhamnose residues by periodate oxidation followed by reduction with borohydride. The hydrolase would also degrade the $D$ rhamnan side-chain of $P$. syringae pv. morsprunorum strain C414, which bears lateral branches of $\beta$-Fuc $f(1 \rightarrow$ and resembles the side-chains of LPSs from Pseudomonas syringae $\mathrm{pv}$. syringae strains 218 and P-55 (Knirel et al. 1988), and the side-chains of $P$. syringae pv. pisi strain 299A, which consist of a D-rhamnan backbone bearing $\beta$-D-GlcNAc branches (Zamze et al., 1985, 1986, and unpublished work). Evidently the phage could be useful for structural studies of side-chains that incorporate a backbone of D-rhamnose.

Preliminary studies have indicated that the activity of the rhamnanase was maximal at $\mathrm{pH} 6.5$ and about $15^{\circ} \mathrm{C}$. At $20^{\circ} \mathrm{C}$, the reaction with intact LPS was nearly complete after $10 \mathrm{~min}$. With other phages, hydrolysis generally occurs over quite wide ranges of $\mathrm{pH}$ and temperature. The hydrolysis catalysed by $\mathrm{A} 7$ under the standard conditions employed resulted in complete removal of side-chain from the lipid A-core oligosaccharide. The relative amounts of hexa- and trisaccharide liberated were not altered by increasing the incubation time or the ratio of phage to LPS. Conditions for hydrolysis were therefore thought to be close to optimal.

Pseudomonas phages with long non-contractile tails exhibit varied morphologies (Bradley, 1967). Usually the tail appendages are distinctive. Phage A7 displayed a fairly complex structure at the tip of its tail, including a baseplate, tail spikes and short fibres. The morphology of A7 is unusual in that other O-antigen-specific phages all belong to the morphology group C of Bradley's classification system, whereas A7 belongs to group B. Initial recognition between a phage and bacterium involves interaction between an attachment protein on the phage and the bacterial receptor. All other O-antigen-specific phages that have been characterized have six copies of the protein attached to the tail base-plate which are responsible for both attachment to the host and the hydrolytic activity. With phage A7, enzymic activity was associated with particles pelleted by centrifugation. Some, if not all, of the enzyme therefore appears to be firmly associated with the intact phage, and it is probable that the tail spikes observed on the viral particle both act as attachment proteins and catalyse the rhamnanase reaction. We have not determined whether free enzyme (dissociated phage tail spikes) was present in lysates or in the supernatant fluid following pelleting of the phage.

Under the electron microscope, LPS may appear to be both strand-like and vesicle-like (e.g. Shands et al., 1967; De Pamphilis, 1971). In reviewing the electron microscopy of isolated LPS, Brogden \& Phillips (1988) observed that the appearance of LPS was dependent on the method used for its extraction, its chemical composition and salt form, and the physicochemical conditions of sample preparation. In particular, uranyl salts stained positively or negatively depending on the salt form of the LPS, and could induce changes in morphology.

Galanos \& Lüderitz (1975) demonstrated that the micellization state of LPS is profoundly affected by the nature of the associated counterion(s). In the present study, the LPS of $P$. syringae pv. morsprunorum appeared to form strands in the presence of phosphotungstate and vesicles with uranyl acetate. Phage A7 was seen attached to vesicles, but not to the strand-like structures, indicating that the orientation of the LPS in the vesicular form perhaps more closely resembles its presentation on the bacterial cell surface. In contrast, Santaolalla \& Esplá (1974) found that LPS of Erwinia carotovora stained with uranyl acetate gave ribbons with a trilaminate structure, but concentric spheroids or chains of oval bodies when stained with phosphotungstate.

As yet, there seems to be no comprehensive fundamental understanding of the relationships between the structure of LPSs, their interaction with heavy metal stains, and their appearance by electron microscopy. In particular, despite the importance of the Pseudomonadaceae, little attention appears to have been paid in these respects to the LPSs that they produce. It would be useful to conduct a systematic study of the effects of salt form and the influence of stains on the electron-microscopical appearance of these LPSs.

\section{ACKNOWLEDGEMENTS}

S.E.Z. was supported by a Cooperative Award in Science and Engineering of the SERC. We thank Mrs K. J. Carter and Dr K. A. D. MacKenzie of Horticulture Research International, East Malling, UK, for GC-MS and assistance with electron 
microscopy, respectively, and the SERC High Field NMR Service, Warwick University, UK, for NMR spectra.

\section{REFERENCES}

Berry, J. M. \& Dutton, G. G. S. (1972). Synthesis of $6-O-(4-O-$ methyl- $\beta$-D-glucopyranosyl)-D-galactose. Can $J$ Chem 50, 14241426.

Björndal, H., Hellerqvist, C. G., Lindberg, B. \& Svensson, S. (1970). Gas-liquid chromatography and mass spectrometry in methylation analysis of polysaccharides. Angew Chem Int Ed 9, 610-618.

Bradley, D. E. (1967). Ultrastructure of bacteriophages and bacteriocins. Bacteriol Rev 31, 230-314.

Brogden, K. A. \& Phillips, M. (1988). The ultrastructural morphology of endotoxins and lipopolysaccharides. Electron Microsc Rev 1, 261-277.

Crosse, J. E. \& Garrett, C. M. E. (1963). Studies on the bacteriophagy of Pseudomonas morsprunorum, Ps. syringae and related organisms. J Appl Bacteriol 26, 159-177.

Crosse, J. E. \& Garrett, C. M. E. (1970). Pathogenicity of Pseudomonas morsprunorum in relation to host specificity. $J$ Gen Microbiol 62, 315-327.

De Pamphilis, M. L. (1971). Dissociation and reassembly of Escherichia coli outer membrane and of lipopolysaccharide, and their reassembly onto flagellar basal bodies. J Bacteriol 105, 1184-1199.

Dubois, M., Gilles, K. A., Hamilton, J. K., Rebers, P. A. \& Smith, F. (1956). Colorimetric method for determination of sugars and related substances. Anal Chem 28, 350-356.

Freigoun, S. O. \& Crosse, J. E. (1975). Host relations and distribution of a physiological and pathological variant of Pseudomonas morsprunorum. Ann Appl Biol 81, 317-330.

Galanos, C. \& Luderitz, O. (1975). Electrodialysis of LPS and their conversion to uniform salt forms. Eur J Biochem 54, 603-610.

Garrett, C. M. E. \& Martins, J. M. S. (1976). Virulence of typical and variant forms of Ps. morsprunorum in leaf scar and wound inoculations. East Malling Res Stn Annu Rep for 1975, 107-108.

Garrett, C. M. E., Panagopoulos, C. G. \& Crosse, J. E. (1966). Comparison of plant pathogenic pseudomonads from fruit trees. J Appl Bacteriol 29, 342-356.

Garrett, C. M. E., Crosse, J. E. \& Sletten, A. (1974). Relations between phage sensitivity and virulence in Pseudomonas morsprunorum. J Gen Microbiol 80, 475-483.

Garrett, C. M. E., Prunier, J. P. \& Crosse, J. E. (1977). Bacterial canker of stone fruits: virulence of typical and variant forms of $P_{s}$. morsprunorum in wound inoculation. East Malling Res Stn Annu Rep for 1976, 127-128.

Knirel, Y. A., Zdorovenko, G. M., Shashkov, A. S., Mamyan, S. S., Yakovleva, L. M., Solyanic, L. P. \& Zakharova, I. Y. (1988). Antigenic polysaccharides of bacteria. 26. Structure of O-specific polysaccharide chains of lipopolysaccharides from $P$ seudomonas cerasi 467 and Pseudomonas syringae pv. syringae strains 218 and P-55, belonging to serogroups II and III. Bioorg Kbim 14, 82-91 (in Russian).

Lindberg, A. A. (1977). Bacterial surface carbohydrates and bac- teriophage adsorption. In Surface Carbobydrates of the Prokaryote Cell, pp. 289-356. Edited by I. W. Sutherland. London: Academic Press.

Quirk, A. V., Sletten, A. \& Hignett, R. C. (1976). Properties of phage receptor lipopolysaccharide from Pseudomonas morsprunorum. $J$ Gen Microbiol 96, 375-381.

Santaolalla, M. \& Esplá, D. (1974). Ultraestructura y composicion quimica del lipopolisacárido de la Erwinia carotovora. Mirrobiol Esp 27, 257-282.

Shands, J. W., Graham, J. A. \& Nath, K. (1967). The morphologic structure of isolated bacterial lipopolysaccharide. $J$ Mol Biol 25, 15-21.

Smith, A. R. W., Zamze, S. E., Munro, S. M., Carter, K. J. \& Hignett, R. C. (1984). Structure of the side-chain of lipopolysaccharide from Pseudomonas syringae pv. morsprunorum strain C28 and its degradation by phage A7. In Proceedings of the Second Working Group on Pseudomonas syringae Pathovars (International Society for Plant Pathology, Sounion, 25-28 April), pp. 83-85. Edited by C. G. Panagopoulos, P. G. Psallidas \& A. S. Alivizatos. Athens: Hellenic Phytopathological Society.

Smith, A. R. W., Zamze, S. E. \& Hignett, R. C. (1985a). Composition of lipopolysaccharide from Pseudomonas syringae pv. morsprunorum and its digestion by bacteriophage A7. J Gen Microbiol 131, 963-974.

Smith, A. R. W., Zamze, S. E., Munro, S. M., Carter, K. J. \& Hignett, R. C. (1985b). Structure of the side-chain of lipopolysaccharide from Pseudomonas syringae pv. morsprunorum C28. Eur J Biochem 149, 73-78.

Smith, A. R. W., Zamze, S. E. \& Hignett, R. C. (1992). Morphology and hydrolytic activity of phage A7, which binds to lipopolysaccharide (LPS) of Pseudomonas syringae pv. morsprunorum (Pseudomonas common antigen). In Second Congress of the International Endotoxin Society, Vienna, 17-20 August, p. 75.

Sweet, D. P., Shapiro, R. H. \& Albersheim, P. (1975). Quantitative analysis by various GLC response-factor theories for partially methylated and partially ethylated alditol acetates. Carbobydr Res 40, 217-225.

Wright, A., McConnell, M. \& Kanagasaki, S. (1980). Lipopolysaccharide as a bacteriophage receptor. In Receptors and Recognition, series B, vol. 7, part I, pp. 29-57. Edited by L. L. Randall \& L. Philipson. London: Chapman \& Hall.

Yokota, S.-I., Kaya, S., Araki, Y., Ito, E., Kawamura, T. \& Sawada, S. (1990). Occurrence of $D$-rhamnan as the common antigen reactive against monoclonal antibody E87 in Pseudomonas aeruginosa IFO 3080 and other strains. J Bacteriol 172, 6162-6164.

Zamze, S. E., Smith, A. R. W. \& Hignett, R. C. (1985). Composition of lipopolysaccharide from strains of Pseudomonas syringae pv. morsprunorum of differing host specificity and virulence. $J$ Gen Microbiol 131, 1941-1950.

Zamze, S. E., Smith, A. R. W. \& Hignett, R. C. (1986). Composition of lipopolysaccharides from Pseudomonas syringae $\mathrm{pv}$. syringae and a serological comparison with lipopolysaccharide from $P$. syringae $\mathrm{pv}$. morsprunorum. J Gen Microbiol 132, 3393-3401.

Received 9 August 1993; revised 5 October 1993; accepted 11 October 1993. 